\title{
Manipulation of the nanoscale heliconical structure of a twist-bend nematic material with polarized light
}

\author{
C. Feng $\odot,{ }^{1,2}$ J. Feng $\odot,{ }^{2}$ R. Saha $\odot,{ }^{4}$ Y. Arakawa $\odot,{ }^{3}$ J. Gleeson, ${ }^{4}$ S. Sprunt $\odot,{ }^{1,4}$ C. Zhu,,${ }^{2, *}$ and A. Jákli ${ }^{1,4, \uparrow}$ \\ ${ }^{1}$ Chemical Physics Interdisciplinary Program, Advanced Materials and Liquid Crystal Institute, Kent State University, Kent, Ohio 44242, USA \\ ${ }^{2}$ Advanced Light Source, Lawrence Berkeley National Lab, Berkeley, California 94720, USA \\ ${ }^{3}$ Department of Applied Chemistry and Life Science, Graduate School of Engineering, Toyohashi University of Technology, \\ Toyohashi, 441-8580, Japan \\ ${ }^{4}$ Department of Physics, Kent State University, Kent, Ohio 44242, USA
}

(Received 8 May 2020; accepted 16 June 2020; published 2 July 2020)

\begin{abstract}
The effect of polarized violet light on the alignment and the heliconical pitch of a liquid crystal dimer containing both sulfur atoms and an azo linkage has been studied by tender resonant x-ray scattering. The results provide evidence of the manipulation of the nanoscale heliconical structure by polarized light. In addition to the bulk alignment of the heliconical nanostructure, the value of the heliconical pitch can be varied as well. After turning the light on, an increase of the pitch is observed in two steps. The increase with a subsecond timescale is attributed to the reduced heliconical order related to trans-cis photoisomerization. This is followed by a smaller increase over a 10-s timescale, which is likely related to the annihilation of defects. After turning the light off, the pitch first decreases within a few seconds to a value larger than the original (before illumination), and then relaxes further on a much longer (hours) timescale.
\end{abstract}

DOI: 10.1103/PhysRevResearch.2.032004

The helical pitch of chiral nematic liquid crystals of rod-shaped molecules ranges from 0.1 to several hundred micrometers [1] depending on the helical twisting power of the molecules. Recently achiral liquid crystal oligomers (dimers [2-18], trimers [17,19,20], and tetramers [11,20,21]), in which rigid arms are connected with flexible methylene spacers consisting of odd-numbered carbons, were found to have a heliconical nanostructure with a pitch in the 6-20-nm range $[5,22,23]$. The heliconical structure involves simultaneous twist and bend deformations of the molecular orientation, but no positional order, hence the name: twist-bend nematic $\left(N_{T B}\right)$ [24-26].

Various methods have been employed to characterize the heliconical structure. Freeze fracture transmission electron microscopy (FFTEM) imaging [5,22] determines values of the pitch with about 1-2-nm precision, but temperature dependent measurements would require a large number of samples to be quenched from various temperatures. Resonant soft x-ray scattering (RSoXS) at the carbon $K$ edge reveals the nanoscale pitch as a function of temperature on single samples [27-30] and can be used for all carbon-containing thermotropic LCs. However, the $\lambda=4.4 \mathrm{~nm}$ wavelength of the carbon $K$ edge limits the resolution of pitch measure-

\footnotetext{
*chenhuizhu@lbl.gov

†ajakli@kent.edu
}

Published by the American Physical Society under the terms of the Creative Commons Attribution 4.0 International license. Further distribution of this work must maintain attribution to the author(s) and the published article's title, journal citation, and DOI. ments to several nanometers. Additionally, RSoXS has only $l \sim 0.3 \mu \mathrm{m}$ penetration depth, thus requiring submicron-thick films [31]. Tender resonant X-ray scattering (TReXS) at the sulfur's $K$ edge (e.g., $E=2.471 \mathrm{keV}, \lambda=0.502 \mathrm{~nm}$ ) enables subnanometer resolution using thicker samples [32-34]. Since TReXS typically comes from just one or two sulfur atoms, well-defined diffraction features can be observed in the entire $N_{T B}$ temperature range [32-35].

Recently in an azo-containing dimer a UV light induced reversible $N_{T B}$ to $N$ transition [36], and six orders of magnitude reversible variation of the viscoelastic properties $[37,38]$ were reported. However, the nanoscale structural changes during these macroscopic transitions have not been studied yet.

In this paper we present TReXS studies of the polarized UV-violet light induced manipulation of the nanoscale structure on a novel dimer material containing both an azo linkage and sulfur atoms. We will show three important effects: (a) The polarized light leads to a bulk metastable alignment of the heliconical axis; (b) due to photoisomerization, the heliconical pitch increases or at sufficiently high light intensities and temperatures the $N_{T B}$ phase can be suppressed; (c) after turning the light off, the pitch relaxes rapidly to a higher value than measured before illumination; further relaxation only occurs on a much slower timescale.

Figure 1(a) shows the molecular structure and phase sequence of the studied dimer, a cyano-terminated azocontaining asymmetric molecule (designated CNAzoS7SCB) whose rigid arms are connected by a $-\left(\mathrm{CH}_{2}\right)_{7}$ - spacer through two sulfur atoms. Details of the molecular synthesis will be published elsewhere.

Polarized optical microscopy (POM) textures of 5- $\mu \mathrm{m}$ planarly aligned CNAzoS7SCB films at temperatures $2{ }^{\circ} \mathrm{C}$ and 


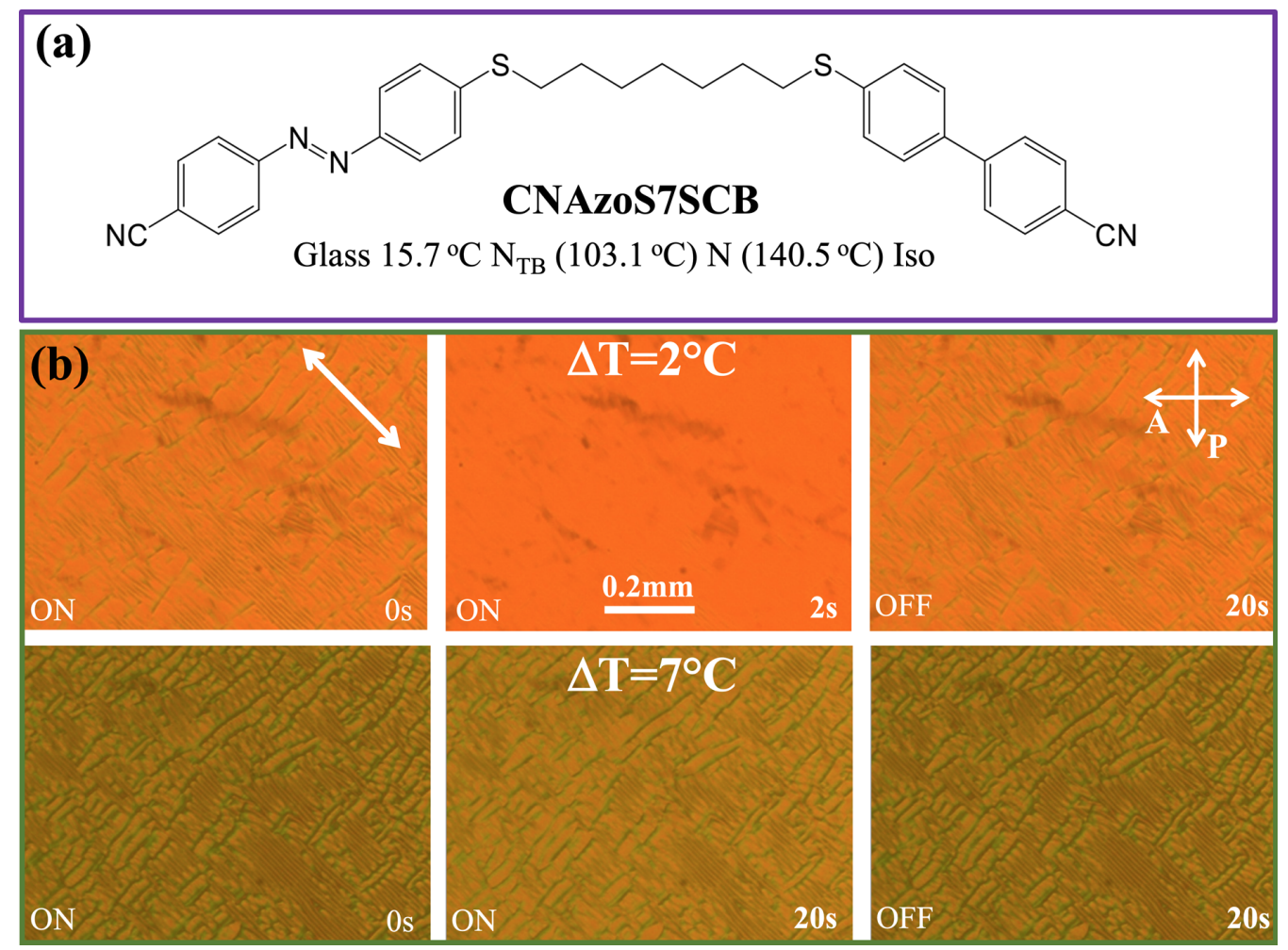

FIG. 1. Molecular structure and polarized optical microscopy (POM) textures of CNAzoS7SCB. (a) Molecular structure and phase sequences determined by POM with crossed polarizers (see crossed arrows on the top right). (b) POM textures of a 5 - $\mu \mathrm{m}$ cell at $2{ }^{\circ} \mathrm{C}$ and $7{ }^{\circ} \mathrm{C}$ below the $N-N_{T B}$ transition temperature before (left), during (middle), and after (right) the sample is illuminated by a 385 -nm-wavelength, $\sim 50-\mathrm{mW} / \mathrm{cm}^{2}$ intensity unpolarized LED light. Thinner stripes before and after illumination are parallel to the rubbing direction of the planar alignment polyimide coating [double headed white arrow shown in the top left picture of (b)].

$7{ }^{\circ} \mathrm{C}$ below the $N-N_{T B}$ phase transition before, during, and after the sample was illuminated by 385 -nm LED light with $50 \mathrm{~mW} / \mathrm{cm}^{2}$ intensity are shown in Fig. 1(b). The periodic thin stripes along the planar alignment direction before (left) and a sufficiently long time after (right) light illumination are characteristic of the $N_{T B}$ phase [39]. The uniform textures formed during the light illumination at $2{ }^{\circ} \mathrm{C}$ below the $N_{T B}-N$ transition temperature (top middle picture) indicate a transition to the $N$ phase induced by the light. At lower temperatures the decrease in the density of the stripes and slight change in the birefringence color (bottom middle photo) indicates a light-induced alteration of the heliconical structure.

TReXS measurements were carried out on the experimental beamline 5.3.1 at the Advanced Light Source (ALS), Lawrence Berkeley National Laboratory. CNAzoS7SCB was melt loaded in between two silicon nitride membranes with the sample thickness being between 5 and $10 \mu \mathrm{m}$. Then the sample cell was attached to a homemade heater housed inside a helium-filled chamber on the beamline. All the samples were initially annealed in the isotropic state to remove heat history and defects. The x-ray beam energy was set at the sulfur $K$ edge $(2471 \mathrm{eV})$ by a channel cut double-bounce silicon monochromator [33]. Small angle diffraction from the heliconical structure was collected on an area detector (Pilatus $300 \mathrm{~K}$, Dectris, Inc.) positioned at a distance of $393 \mathrm{~mm}$ from the sample. The beam center and the sample-to-detector distance were calibrated using both silver behenate and the smectic- $A$ density wave of $4{ }^{\prime}$ - $n$-octyl-4-cyano-biphenyl (8CB) with XI-CAm [40] and NIKA [41] software. A 405-nm polarized violet laser was used to illuminate the sample with approximately $50 \mathrm{~mW} / \mathrm{cm}^{2}$ intensity. No resonant diffraction at the finite scattering vector was observed in the uniaxial nematic (N) phase.

The temperature dependence of the heliconical pitch in the $N_{T B}$ phase and typical two-dimensional (2D) scattering patterns from the heliconical structure are shown in Fig. 2. The results measured in darkness (black dots) and during exposure to the polarized laser light (blue squares) are shown in the main pane. The pitch is calculated from the wave number $q=2 \pi / p$ where the diffracted $\mathrm{x}$-ray intensity has a maximum. Typical 2D TReXS patterns in darkness and during illumination are shown in insets (a) and (b), respectively. The scattering pattern is circular in the dark state [Fig. 2(a)] with maximum intensity at scattering wave number $q_{d}$, corresponding to domains with random alignment of the heliconical axis. The pattern during illumination is split into an ellipse with semimajor axis corresponding to scattering wave number $q_{a}$ perpendicular to the polarization of the light (purple doubleheaded arrow), and a circle with radius $q_{u}$ and scattering maxima off the long axis of the ellipse. Everywhere in this paper "aligned" refers to domains aligned perpendicular to the polarization of the laser, and "unaligned" describes domains that are neither parallel nor perpendicular to the polarization. A sketch of the effect of the polarized light on the alignment 


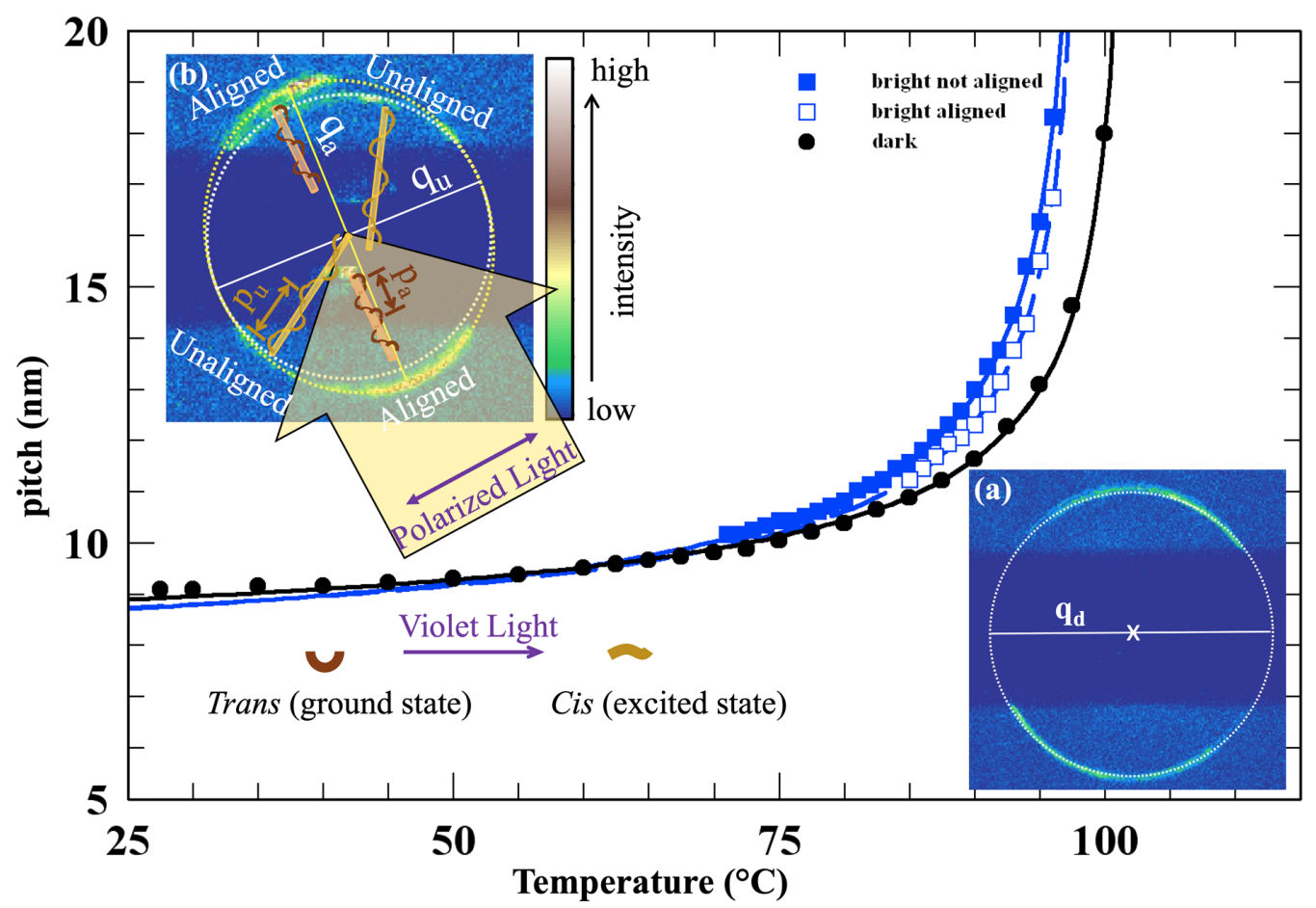

FIG. 2. Temperature dependences of the heliconical pitch of CNAzoS7SCB measured in dark (black dots) and during about $50 \mathrm{~mW} / \mathrm{cm}^{2}$ intensity 405-nm-wavelength polarized laser light (hollow and solid blue square for aligned and unaligned domains, respectively). Typical 2D scattered patterns in dark state at $\Delta T=5^{\circ} \mathrm{C}$ and during violet light illumination at $\Delta T=3{ }^{\circ} \mathrm{C}$ are shown in insets (a), (b), respectively. Overlaid on inset (b) is the schematic structures of the aligned and unaligned heliconical domains. The approximate shapes of the molecules in the dark trans and the light induced cis states are shown below the data points. The darker blue strip enclosed by black dotted lines in the horizontal direction is the shadow of the beam stop that was between the detector and the sample, i.e., not right in front of the detector.

and pitch with the illustration of the molecular shapes in trans and cis forms are also shown in the inset (b) of Fig. 2.

These features are related to the trans-cis photoisomerization process, whereby the relaxed trans conformation continues to be excited until it aligns perpendicular to the polarization direction of the light [42]. While in nematic materials the director randomizes soon after removal of the orienting optical field [43] and azo units have to be incorporated in the surface for permanent alignment [44], in the $N_{T B}$ phase the bulk alignment of the heliconical axis is metastable in the absence of the field even without an alignment layer. This is related to the pseudolayered structure of the $N_{T B}$ phase, which behaves analogously to a true smectic phase, where UV light induced permanent alignment of the layers has previously been demonstrated [45]. The observation that $q_{a}>q_{u}$ implies a smaller pitch of the domains oriented perpendicular to the polarization, i.e., $p_{a}<p_{u}$, as illustrated in inset (b) of Fig. 2. However, both $p_{a}$ and $p_{u}$ are larger than the pitch $p_{d}$ in the dark state (before illumination) since the $N$ to $N_{T B}$ transition temperature is effectively lowered by the exposure to the absorbing light. As this is related to the trans-cis isomerization induced destabilization of the heliconical order, we conclude that even the aligned domains have cis conformers, although less extent than in the unaligned domains.

The temperature dependences of the pitch $p=2 \pi / q$ for dark state (black dots), for aligned and unaligned domains during illumination (open and solid blue squares), could be equally well fitted to the expression $p(T)=$
$p_{o}+\Delta p\left(1-T / T_{c}\right)^{-\gamma}$, where $p_{o}$ is the asymptotic pitch value very far from the critical temperature $T_{c}$, which is slightly larger than the $N-N_{T B}$ phase transition temperature; the parameter $\Delta p$ is the coefficient of the temperature dependent term, and $\gamma$ is the exponent. Based on predictions by meanfield theories [23,24,46], Fig. 2 shows the fits with $\gamma=1 / 2$ where the best fit gave $p_{o}=7.1,6.8$, and $6.6 \mathrm{~nm}, \Delta p=1.56$, 1.65 , and $1.86 \mathrm{~nm}$ and $T_{c}=102.1^{\circ} \mathrm{C}, 98.7^{\circ} \mathrm{C}$, and $98.5^{\circ} \mathrm{C}$ for the dark, bright aligned, and bright unaligned states, respectively. Far from the transition the effect of light is expected to be negligible, so one would expect $p_{o}$ to be the same for all three cases. The differences of the fit values are due to the fact the $\gamma=1 / 2$ value is probably valid only near $T_{o}$. The small increase of $\Delta p$ for the bright unaligned state is related to the larger portion of the molecules in cis configuration that perturb the heliconical packing. The decrease of $T_{c}$ in the bright states can be attributed to the light absorption induced heating, which is largest for the bright unaligned state.

We also analyzed the peak widths along the alignment and several other directions. From the full width at half maximum (FWHM), we determined the correlation length of the heliconical bond order $\xi$ as $\xi=1 /$ FWHM. The correlation length was found to increase on cooling. The values at $\Delta T=$ $3{ }^{\circ} \mathrm{C}$ were between 50 and $75 \mathrm{~nm}$ without showing much correlation to the orientation of the heliconical axis.

Representative 2D TReXS scattering patterns at $2{ }^{\circ} \mathrm{C}, 3{ }^{\circ} \mathrm{C}$, and $5^{\circ} \mathrm{C}$ below the dark $N-N_{T B}$ phase transition before, during 

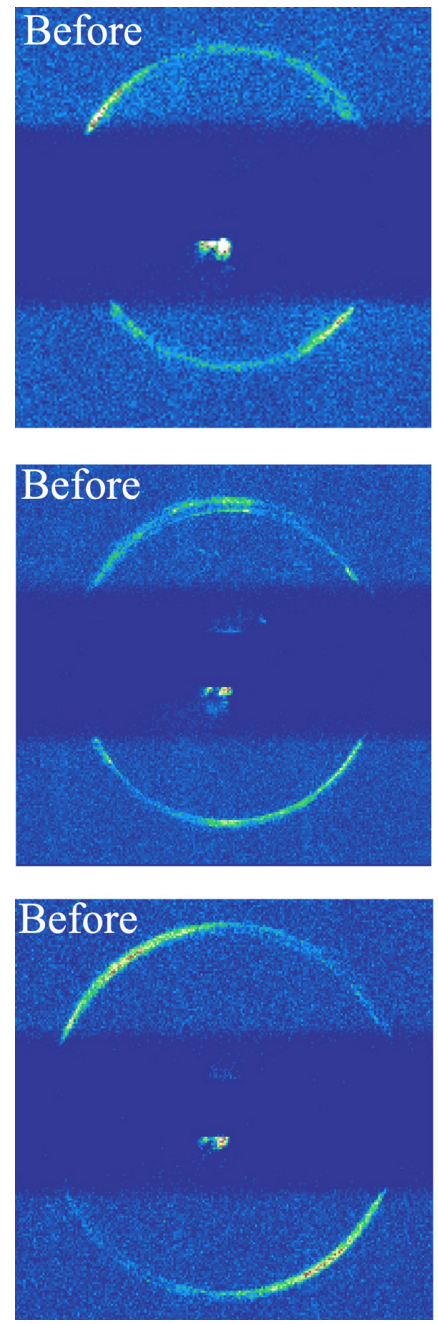
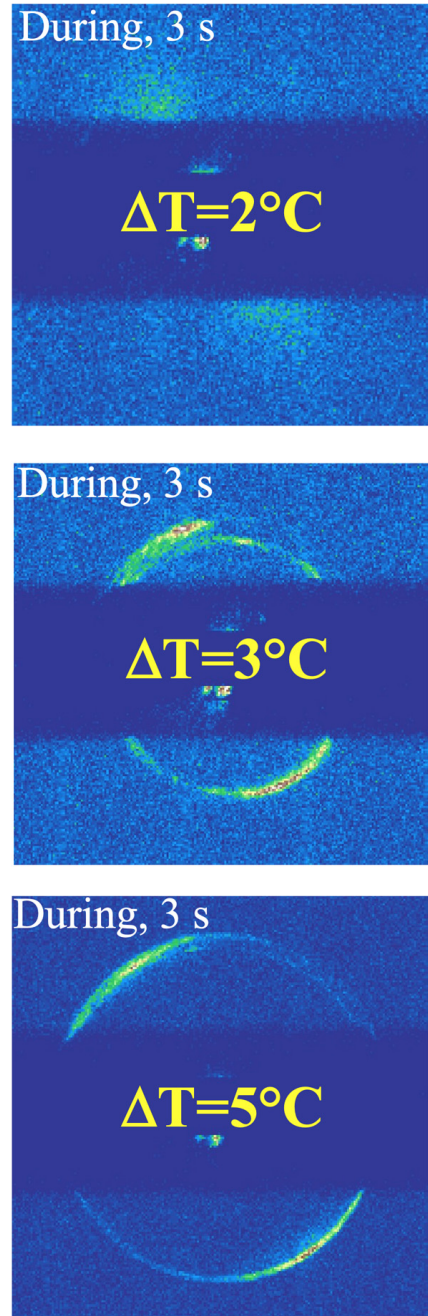
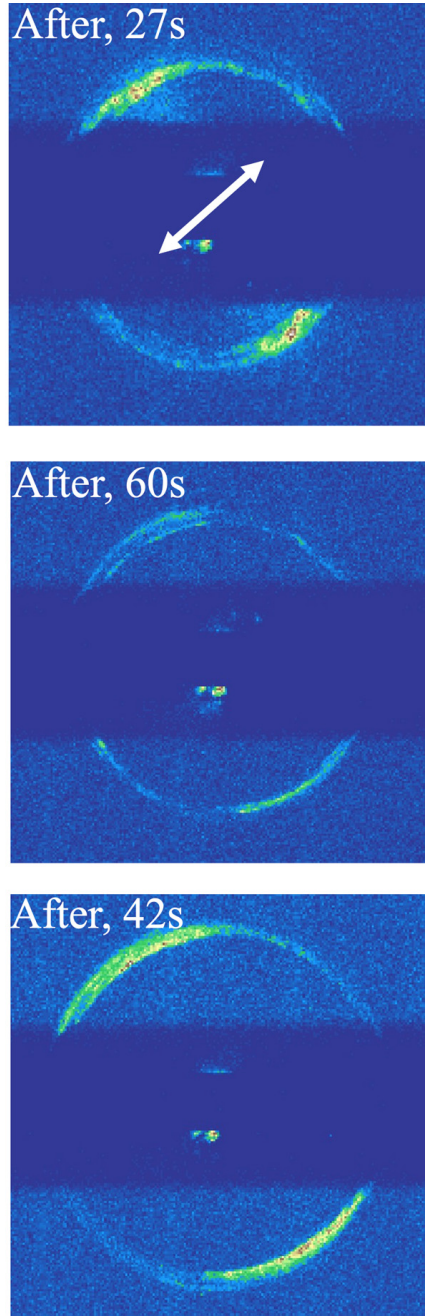

FIG. 3. Representative $2 \mathrm{D}$ TReXS scattering patterns at $2{ }^{\circ} \mathrm{C}, 3{ }^{\circ} \mathrm{C}$, and $5{ }^{\circ} \mathrm{C}$ below the dark $N$ - $N_{T B}$ phase transition before (left), during $3 \mathrm{~s}$ of illumination (middle), and at different times after the polarized light turned off (right). Top row: $\Delta T=T_{N-N_{T B}}-T=2{ }^{\circ} \mathrm{C}$; middle row: $\Delta T=3{ }^{\circ} \mathrm{C}$; bottom row: $\Delta T=5^{\circ} \mathrm{C}$.

$3 \mathrm{~s}$ of illumination, and at different times after the polarized light is turned off are shown in Fig. 3. There are several notable features. At $\Delta T=2{ }^{\circ} \mathrm{C}$ in less than $3 \mathrm{~s}$ after exposure to the light (top middle image) the diffraction peak disappears, suggesting unwinding of the heliconical structure. After the light is switched off (top right), the diffraction peaks re-form, but they are mainly aligned normal to the polarization direction of the light (white double-headed arrow), even though the orientation of the heliconical axis was almost random before the illumination (top left). At $\Delta T=3{ }^{\circ} \mathrm{C}$ (middle row), the light leads to a decrease of the wave number of the heliconical structure within $3 \mathrm{~s}$ and induces alignment (middle image). After turning the light off, the wave number decreases, and the alignment fades away (right image). Starting from an aligned sample at $\Delta T=5{ }^{\circ} \mathrm{C}$ (bottom row), the alignment remains unchanged both during the illumination (middle) and while the pitch increases after the light was turned off (right). These observations clearly demonstrate that the light affects both the value of the pitch and the alignment of the heliconical axis. The alignment was found to be metastable with relaxation time increasing strongly on cooling.
The time dependences of the heliconical wave number at $\Delta T=2{ }^{\circ} \mathrm{C}, 3{ }^{\circ} \mathrm{C}$, and $5{ }^{\circ} \mathrm{C}$, after the 405 -nm polarized light is first switched on and then subsequently off, are shown in Fig. 4.

As already demonstrated in Fig. 3, when we turn the light on at $\Delta T=2{ }^{\circ} \mathrm{C}$, the scattering ring disappears (dotted green arrow), i.e., $q<0.2 \mathrm{~nm}^{-1}$. This happens in less than $3 \mathrm{~s}$ (before the next x-ray exposure). The $q$ value decreases to $q>0.2 \mathrm{~nm}^{-1}$, i.e., the heliconical pitch increases, but not unwound at lower temperatures. We find that the time dependence of the $q$ values could be fitted by the combination of two exponential decays. The fast decay times are less or equal to $1 \mathrm{~s}$, while the slower decay times are over $10 \mathrm{~s}$. Both the fast and slow switching times are larger for the aligned domains (open symbols with dotted fitting curves) than for the unaligned domains (solid symbols and continuous fitting lines), and both increase on cooling. Considering the less than $10-\mu \mathrm{m}$ film thickness, the temperature increase related to the light absorption occurs on a millisecond timescale [42], i.e., not visible in our measurements. For this reason, the fast switching is attributed to the decreasing 


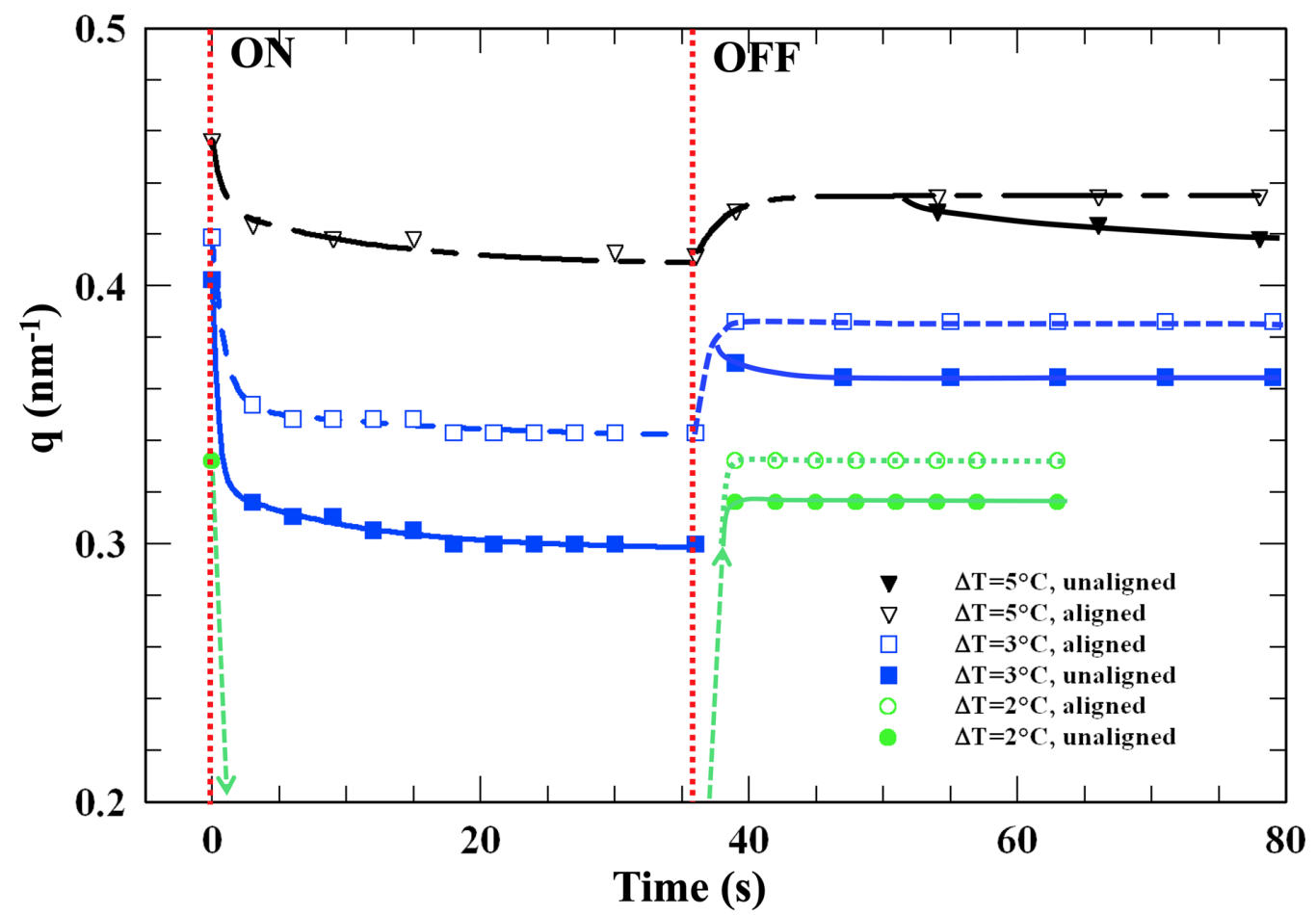

FIG. 4. Time dependence of the wave number $q$ after the polarized violet light is turned on at $t=0$ and off at $t=36 \mathrm{~s}$. Note the smallest time difference between two consecutive measurements was $3 \mathrm{~s}$, as the TReXS exposure time was $2 \mathrm{~s}$. Green dotted arrows for $\Delta T=2{ }^{\circ} \mathrm{C}$ indicate that the wave number decreases below $q=0.2 \mathrm{~nm}^{-1}$ in less than $3 \mathrm{~s}$ after turning the light on, and increases above $0.2 \mathrm{~nm}^{-1}$ after turning the light off. Solid symbols and continuous lines refer to unaligned domains, whereas open symbols with dotted lines describe behavior of aligned domains. The blue dotted and continuous and black dotted lines after the light turned on at $\Delta T=3{ }^{\circ} \mathrm{C}$ and $5{ }^{\circ} \mathrm{C}$ are fit equations using double exponential functions. The black dotted line at $\Delta T=5^{\circ} \mathrm{C}$ after the light is turned off is a fit to a single exponential. Other lines are only a guide to the eye.

order parameter due to photoisomerization. The slow response is most likely related to defect annihilation. This is faster toward higher temperatures, when the heliconical order is weaker.

After the light is turned off, the wave numbers of the heliconical structure increase quickly $(<2 \mathrm{~s})$, except for $\Delta T=$ $5^{\circ} \mathrm{C}$, when a single exponential with a characteristic time of $2 \mathrm{~s}$ describes the time dependence of the wave number in the aligned domains (see black dotted curve). Although in the timescale shown in the graph, the $q_{a}$ values after $10 \mathrm{~s}$ appear constant, measurements repeated after $10 \mathrm{~min}$ showed a very slow increase toward the original values (the lower the temperature, the slower this increase). This again can be explained by defect annihilation, which now is much slower than during the illumination, as the annihilation is not expedited by the light induced reduction of the heliconical order. Finally, after turning the illumination off, the heliconical structure recovers with the pitch in both aligned and unaligned domains decreasing with time, but at different rates. At $\Delta T=2{ }^{\circ} \mathrm{C}$ we observe the recovery of both $q_{a}$ and $q_{u}$ peaks within $3 \mathrm{~s}$. At lower temperatures the $q_{u}$ peaks appear later via splitting the peak to $q_{a}$ and a lower value that eventually reaches $q_{u}$. This is especially clear for $\Delta T=5^{\circ} \mathrm{C}$, where first only the peaks with $q_{a}$ appear; then the splitting happens more than $10 \mathrm{~s}$ after the appearance of $q_{a}$. This illustrates that the alignment is fading via the spontaneous growth of unaligned domains. Such a fading memory may offer some applications, such as mapping the polarization and intensity of a focused light with $10-\mathrm{nm}$ resolution, providing an alternative for the currently used Mach-Zehnderlike interferometers [47] and Shack-Hartmann wave front sensors [48].

To summarize, we presented TReXS studies of the polarized violet light induced manipulation of the nanoscale heliconical structure in a novel dimer material containing both sulfur atoms and an azo linkage. We found three important effects: (a) A polarized UV-violet light leads to a bulk metastable alignment of the heliconical axis of the $N_{T B}$ phase; (b) due to photoisomerization, the heliconical pitch increases and, at temperatures sufficiently close to the $N_{T B}-N$ transition, can be completely unwound; (c) after turning the light off, the heliconical structure recovers, first reaching a metastable state with higher pitch than before illumination, which subsequently relaxes toward the initial (equilibrium) pitch on a much slower timescale.

This research was supported by the National Science Foundation under Grant No. DMR-1904167. We acknowledge use of Beamlines 5.3.1 of ALS supported by the Director of the Office of Science, Office of Basic Energy Sciences, of the US Department of Energy under Contract No. DE-AC0205CH11231. C.F. is partially supported by the ALS Doctoral Fellowship. A.J. acknowledges useful discussions with T. Kósa. 
[1] P.-G. de Gennes, The Physics of Liquid Crystals, 2nd ed. (Clarendon Press, Oxford, 1974).

[2] J. W. Emsley, G. R. Luckhurst, G. N. Shilstone, and I. Sage, Mol. Cryst. Liq. Cryst. 102, 223 (1984).

[3] P. J. Barnes, A. G. Douglass, S. K. Heeks, and G. R. Luckhurst, Liq. Cryst. 13, 603 (1993).

[4] M. Cestari, E. Frezza, A. Ferrarini, and G. R. Luckhurst, J. Mater. Chem. 21, 12303 (2011).

[5] V. Borshch, Y.-K. Kim, J. Xiang, M. Gao, A. Jakli, V. P. Panov, J. K. Vij, C. T. Imrie, M. G. Tamba, G. H. Mehl, and O. D. Lavrentovich, Nat. Commun. 4, 2635 (2013).

[6] K. Adlem, M. Čopič, G. R. Luckhurst, A. Mertelj, O. Parri, R. M. Richardson, B. D. Snow, B. A. Timimi, R. P. Tuffin, and D. Wilkes, Phys. Rev. E 88, 022503 (2013).

[7] J. W. Emsley, M. Lelli, G. R. Luckhurst, and H. Zimmermann, Phys. Rev. E 96, 062702 (2017).

[8] M. Cestari, S. Diez-Berart, D. A. Dunmur, A. Ferrarini, M. R. de la Fuente, D. J. B. Jackson, D. O. Lopez, G. R. Luckhurst, M. A. Perez-Jubindo, R. M. Richardson, J. Salud, B. A. Timimi, and H. Zimmermann, Phys. Rev. E 84, 031704 (2011).

[9] B. Robles-Hernández, N. Sebastián, M. R. de la Fuente, D. O. López, S. Diez-Berart, J. Salud, M. B. Ros, D. A. Dunmur, G. R. Luckhurst, and B. A. Timimi, Phys. Rev. E 92, 062505 (2015).

[10] Y. Arakawa, K. Komatsu, and H. Tsuji, New J. Chem. 43, 6786 (2019).

[11] Z. Parsouzi, G. Babakhanova, M. Rajabi, R. Saha, P. Gyawali, T. Turiv, H. Wang, A. R. Baldwin, C. Welch, G. H. Mehl, J. T. Gleeson, A. Jakli, D. Lavrentovich, and S. Sprunt, Phys. Chem. Chem. Phys. 21, 13078 (2019).

[12] C. T. Archbold, E. J. Davis, R. J. Mandle, S. J. Cowling, and J. W. Goodby, Soft Matter 11, 7547 (2015).

[13] A. A. Dawood, M. C. Grossel, G. R. Luckhurst, R. M. Richardson, B. A. Timimi, N. J. Wells, and Y. Z. Yousif, Liq. Cryst. 43, 2 (2016).

[14] C. T. Archbold, R. J. Mandle, J. L. Andrews, S. J. Cowling, and J. W. Goodby, Liq. Cryst. 44, 84 (2017).

[15] R. J. Mandle and J. W. Goodby, Liq. Cryst. 44, 656 (2017).

[16] F. F. P. Simpson, R. J. Mandle, J. N. Moore, and J. W. Goodby, J. Mater. Chem. C 5, 5102 (2017).

[17] Y. Arakawa, K. Komatsu, S. Inui, and H. Tsuji, J. Mol. Struct. 1199, 126913 (2020).

[18] K. L. Atkinson, S. M. Morris, F. Castles, M. M. Qasim, D. J. Gardiner, and H. J. Coles, Phys. Rev. E 85, 012701 (2012).

[19] M. R. Tuchband, D. A. Paterson, M. Salamończyk, V. A. Norman, A. N. Scarbrough, E. Forsyth, E. Garcia, C. Wang, J. M. D. Storey, D. M. Walba, S. Sprunt, A. Jákli, C. Zhu, C. T. Imrie, and N. A. Clark, Proc. Natl. Acad. Sci. USA 116, 10698 (2019).

[20] R. J. Mandle and J. W. Goodby, RSC Adv. 6, 34885 (2016).

[21] R. Saha, G. Babakhanova, Z. Parsouzi, M. Rajabi, P. Gyawali, C. Welch, G. H. Mehl, J. Gleeson, O. D. Lavrentovich, S. Sprunt, and A. Jakli, Mater. Horizons 6, 1905 (2019).
[22] D. Chen, J. H. Porada, J. B. Hooper, A. Klittnick, Y. Shen, M. R. Tuchband, E. Korblova, D. Bedrov, D. M. Walba, M. A. Glaser, J. E. Maclennan, and N. A. Clark, Proc. Natl. Acad. Sci. USA 110, 15931 (2013).

[23] A. Jákli, O. D. Lavrentovich, and J. V. Selinger, Rev. Mod. Phys. 90, 045004 (2018).

[24] I. Dozov, Europhys. Lett. 56, 247 (2001).

[25] V. P. Panov, M. Nagaraj, J. K. Vij, Y. P. Panarin, A. Kohlmeier, M. G. Tamba, R. A. Lewis, and G. H. Mehl, Phys. Rev. Lett. 105, 167801 (2010).

[26] C. Meyer, G. R. Luckhurst, and I. Dozov, Phys. Rev. Lett. 111, 067801 (2013).

[27] C. Zhu, M. R. Tuchband, A. Young, M. Shuai, A. Scarbrough, D. M. Walba, J. E. Maclennan, C. Wang, A. Hexemer, and N. A. Clark, Phys. Rev. Lett. 116, 147803 (2016).

[28] M. R. Tuchband, M. Shuai, K. A. Graber, D. Chen, C. Zhu, L. Radzihovsky, A. Klittnick, L. Foley, A. Scarbrough, J. H. Porada, M. Moran, J. Yelk, E. Korblova, D. M. Walba, A. Hexemer, J. E. Maclennan, A. Matthew, and N. A. Clark, arXiv:1703.10787v1.

[29] M. Salamończyk, N. Vaupotič, D. Pociecha, C. Wang, C. Zhu, and E. Gorecka, Soft Matter 13, 6694 (2017).

[30] W. D. Stevenson, Z. Ahmed, X. B. Zeng, C. Welch, G. Ungar, and G. H. Mehl, Phys. Chem. Chem. Phys. 19, 13449 (2017).

[31] B. L. Henke, E. M. Gullikson, and J. C. Davis, At. Data Nucl. Data Tables 54, 181 (1993).

[32] M. Salamończyk, R. J. Mandle, A. Makal, A. Liebman-Peláez, J. Feng, J. W. Goodby, and C. Zhu, Soft Matter 14, 9760 (2018).

[33] Y. Cao, J. Feng, A. Nallapaneni, Y. Arakawa, K. Zhao, G. H. Mehl, F. Liu, and C. Zhu, arXiv:1907.11330.

[34] E. Cruickshank, M. Salamończyk, D. Pociecha, G. J. Strachan, J. M. D. Storey, C. Wang, J. Feng, C. Zhu, E. Gorecka, and C. T. Imrie, Liq. Cryst. 46, 1595 (2019).

[35] R. Saha, C. Feng, C. Welch, G. H. Mehl, J. Feng, C. Zhu, J. Gleeson, S. Sprunt, and A. Jákli (unpublished).

[36] D. A. Paterson, J. Xiang, G. Singh, R. Walker, M. AgraKooijman, A. Martínez-Felipe, M. Gao, J. M. D. Storey, S. Kumar, O. D. Lavrentovich, and C. T. Imrie, J. Am. Chem. Soc. 138, 5283 (2016).

[37] S. Aya, P. Salamon, D. A. Paterson, J. M. D. Storey, C. T. Imrie, F. Araoka, A. Jákli, and Á. Buka, Adv. Mater. Interfaces 6, 1802032 (2019).

[38] S. Aya, P. Salamon, D. A. Paterson, J. M. D. Storey, C. T. Imrie, F. Araoka, A. Jákli, and Á. Buka, J. Vis. Exp., e60433 (2019).

[39] P. K. Challa, V. Borshch, O. Parri, C. T. Imrie, S. N. Sprunt, J. T. Gleeson, O. D. Lavrentovich, and A. Jákli, Phys. Rev. E 89, 060501(R) (2014).

[40] R. J. Pandolfi, D. B. Allan, E. Arenholz, L. Barroso-Luque, S. I. Campbell, T. A. Caswell, A. Blair, F. De Carlo, S. Fackler, A. P. Fournier, G. Freychet, M. Fukuto, D. Gürsoy, Z. Jiang, H. Krishnan, D. Kumar, R. J. Kline, R. Li, C. Liman, S. Marchesini et al., J. Synchrotron Radiat. 25, 1261 (2018).

[41] J. Ilavsky, Appl. Crystallogr. 45, 324 (2012).

[42] Opticals Effects in Liquid Crystals, edited by I. Jánossy (Springer, Netherlands, Dordrecht, 1991). 
[43] Y. Wu, J. I. Mamiya, A. Kanazawa, T. Shiono, T. Ikeda, and Q. Zhang, Polymer 40, 4787 (1999).

[44] S. T. Sun, W. M. Gibbons, and P. J. Shannon, Nature 351, 49 (1991).

[45] I. Jánossy, A. Jákli, G. G. Nair, K. K. Raina, and T. Kósa, Mol. Cryst. Liq. Cryst. Sci. Technol., Sect. A 329, 507 (1999).
[46] S. M. Shamid, S. Dhakal, and J. V. Selinger, Phys. Rev. E 87, 052503 (2013).

[47] R. Dorn, S. Quabis, and G. Leuchs, Phys. Rev. Lett. 91, 233901 (2003).

[48] D. R. Neal, J. Copland, and D. A. Neal, Adv. Charact. Tech. Opt. Semicond. Data Storage Compon. 4779, 148 (2002). 